\title{
POWER QUALITY IMPROVEMENT IN A WEAK BUS SYSTEM USING FACTS CONTROLLER
}

\author{
P. C. Pradhan ${ }^{1}$, P. K. Ray ${ }^{2}$, R. K. Sahu ${ }^{3}$, J. K. Moharana ${ }^{4}$ \\ ${ }^{I}$ Faculty and Research Scholar, Dept.of EE, DRIEMS,CUttack,pratap_pin@yahoo.com \\ ${ }^{2}$ Dept. of EEE, IIIT, BBSR, pkrayiiit@gmail.com \\ ${ }^{3}$ Dept. of EE, VSSUT, Burla, rksahu123@gmail.com \\ ${ }^{4}$ Dept. of EEE, GITA, BBSR, jkrushna@gmail.com
}

\begin{abstract}
Power quality management is the main problem that the industry is facing today. This is mainly affected by the generation of harmonics. The growing use of electronic equipment produces a large amount of harmonics in distribution systems because of nonsinusoidal currents consumed by non-linear loads. As we know for the better quality of power, the voltage and current waveforms should be sinusoidal, but in actual practice it is somewhat disturbed and this phenomenon is called "Harmonic Distortion". Voltage harmonics are generally present in supply of power from utility. Even though electronic and non-linear devices are flexible, economical and energy efficient, they may degrade power quality by creating harmonic currents and consuming excessive reactive power. The STATCOM as FACTS controller can be applied to a single non-linear load or many. It provides controlled current injection to remove harmonic current from the source side of electric system and also can improve the power factor.
\end{abstract}

Keywords-: Controller design, PI Controller, FACTS and STATCOM. ****

\section{INTRODUCTION}

Harmonic pollution is not a new phenomenon, issues of harmonic components of voltage and / or current curves occurred early in the industrial use of electricity, the first mention regarding to the use of harmonic analysis as a way of solving a practical electrical engineering problem, was made in 1893 by Steinmetz. Nowadays, in modern industry, about 50\% of receivers an industrial customer are supplied using frequency converters (AC and DC adjustable drives), switching mode power supply (for powering computer systems or process controllers) and electronic ballasts. Due to the non-linear characteristics of these receivers (using diodes, thyristors or transistors to convert $\mathrm{AC}$ voltage in $\mathrm{DC}$ voltage and $\mathrm{DC}$ voltage in $\mathrm{AC}$ voltage or DC voltage in DC voltage), in industrial distribution systems harmonic currents occur. These, harmonic currents, leads to the distortion of the voltage curve at the point of common coupling (and in other parts of the distribution system), so are affected and other customers, non-harmonic polluting [1, 2]. Resonance phenomena can increase the harmonic components of voltage that will lead to increase the voltage in different parts of the electricity supply system, overloading of transformers and, in particular capacitor [3]. Also, can causing losses increasing in overhead electric lines, cable, transformers and capacitor banks, leading to acceleration of insulation aging and reduction life. In four wire systems, harmonic current with frequency multiple by three will be add up in the neutral conductor, so the current through this reaches high values. Given the negative consequences of harmonic distortion the measures must be taken that would lead to limitation of harmonic pollution in power networks. Measures can be undertaken involving: reduce harmonic currents from customers, changing the resonance frequency and filtering of the harmonic distortion using passive, active or hybrid systems.

The filter design has become essential for distribution systems. This work examines the feasibility of designing a filter size such that the total investment cost, (in which unacceptable voltage profiles must be correct and harmonic must be reduced within the permissible maximal value e.g. IEEE Std. 519 [4]), is keep at a minimum. Designing a harmonic filter has conventionally been by a trial and error approach. Various formulations for a more systematic approach to design harmonic filters have been developed in the decade [1-3, 5-7]. Although effective in eliminating the harmonic, some of these methods did not consider the cost of filter elements. Moreover, other related investigation did not address whether or not the issue of the filters can adhere to the industrial specifications. The harmonic filter design problem has a partially discrete, partially continuous formulation with a non-differentiable nonlinear objective function. The non-differentiable nature, originating from a circumstance in which the cost of capacitors is step-wise, makes most nonlinear optimization techniques difficult to apply. This type of problems has generally been tackled by heuristic or approximate techniques. Simulation results have been shown in this paper. 
As is well known, the current is proportional to the voltage in case of a linear load as shown in Fig.1 (a) whereas the current is not proportional to the voltage in case of non-linear load (as shown in Fig.1 (b)). A linear load draws active power from the grid with only fundamental component being present in the current and absorbs/injects reactive power from/to the grid. However, a non-linear load draws active power from the grid, where the current has fundamental and harmonics. These harmonics do not provide extra power but unnecessarily, yet unavoidably, increase the system volt-ampere (VA). This shows up as an increase in the rms current in the lines and leads to an extra heating of the transmission conductors and system elements. Hence, the compensation of reactive power is necessary for both linear and non-linear loads. Harmonic compensation upto standard values and power factor improvement are the main issues for such loads. The power factor $P F$ is defined as the ratio of the active power $P$ to the apparent power $S$. Thus

$$
P F=\frac{P}{S}
$$

For purely sinusoidal voltage and current, the standard expression is obtained as

$$
P F=\cos \phi
$$

Where $\cos \phi$ is popularly known as the displacement factor. The classical expression of the power factor does not apply for non-sinusoidal current due to non-linear load. Hence, for sinusoidal voltage and non-sinusoidal current, equation (1) can be expressed as:

$$
\begin{aligned}
P F & =\frac{V_{s, r m s} I_{s 1, r m s} \cos \phi}{V_{s, r m s} I_{s, r m s}} \\
& =\frac{I_{s 1, r m s} \cos \phi}{I_{s, r m s}} \\
& =K_{p} \cos \phi
\end{aligned}
$$

The factor $K_{p}=\frac{I_{s 1, r m s}}{I_{s, r m s}}$ is a measure of the harmonic content of the current and is 1.0 at best when there is no harmonics. Hence, $P F$ depends on both the harmonic content and the displacement factor $(\cos \phi) . K_{p}$ is also related to the total harmonic distortion $\left(\mathrm{THD}_{i}\right)$.

$$
K_{p}=\frac{1}{\sqrt{1+T H D_{i}^{2}}}
$$

The total harmonic distortion is expressed as

$$
T H D_{i}=\frac{\sqrt{\sum_{n=2}^{\infty} I_{s n, r m s}^{2}}}{I_{s 1, r m s}}
$$

Hence, in conventional ac supplies, power factor improvement means compensation of the displacement factor. In a more general sense, the improvement of the power factor (equation (3)) to unity involves two issues:

(i) Improvement of fundamental power factor or displacement factor: For example: (a) $\cos \phi=1.0$ for $R$-load linear and $\cos \phi<1.0$ for $R-L$ and $R-C$ load also linear. (b) For diode rectifier load, $\cos \phi=1.0$ (assuming that DC load current is continuous) and for an SCR (silicon controlled rectifier), $\cos \phi=\cos \alpha$ where $\alpha$ is the triggering angle of $\mathrm{SCR}$. The fundamental power factor can be made unity by reactive power compensation.

(ii) Presence of harmonics, increases true rms $I_{s, r m s}\left[=\sqrt{I_{s 1, r m s}^{2}+\sum I_{s n, r m s}^{2}}\right]$ and hence also increases the system $V A(=S)$. Clearly, therefore, $V A R$ is increased. But $\frac{I_{s 1, r m s}}{I_{s, r m s}}$ is unity always for $R, R-L$ and $R-L-C$ loads in conventional ac systems feeding linear loads, whereas, $\frac{I_{s 1, r m s}}{I_{s, r m s}}$ will never be unity for non-linear load unless $\sqrt{\sum I_{s n, r m s}^{2}}=0$. So, the only option is harmonic compensation which is also known as active filtration. The survey of the power factor for a year of the rural consumers is given in Table.I and spectrum analysis of the supply current is shown in Fig.2. Fig.2 shows the spectrum analysis of supply current before compensation. The Total harmonic Distortion of the supply current is $30.44 \%$. 


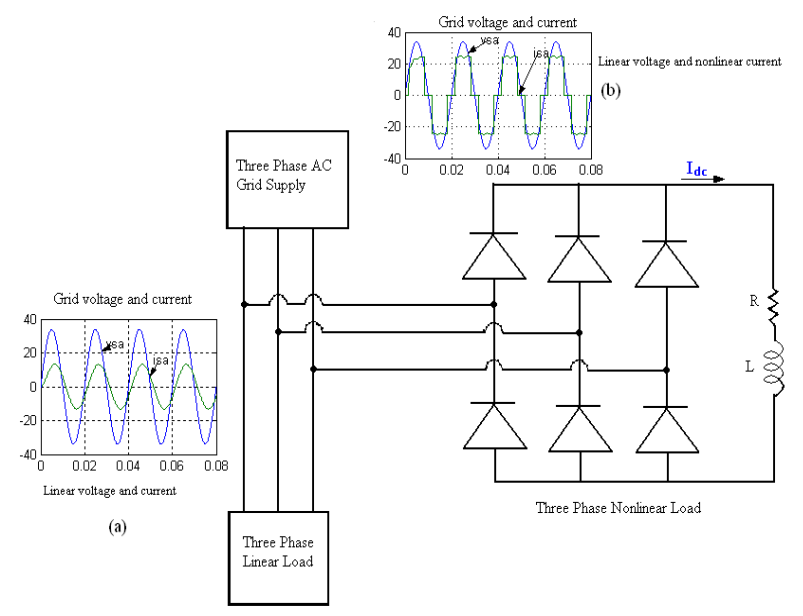

Fig.1: Linear and non-linear loads of consumers connected to supply system

Table 1: It shows the power factor of the rural consumers

\begin{tabular}{|c|l|l|l|}
\hline $\begin{array}{c}\text { Period of the } \\
\text { Year } \\
\text { (Month) }\end{array}$ & $\begin{array}{l}\text { Actual } \\
\text { KW } \\
\text { Demand } \\
\text { (KW) }\end{array}$ & $\begin{array}{l}\text { Actual } \\
\text { KVA } \\
\text { Demand } \\
\text { (KVA) }\end{array}$ & $\begin{array}{l}\text { Actual Power } \\
\text { Factor (\%) }\end{array}$ \\
\hline January & 200 & 245 & $\mathbf{8 1 . 6 3 \%}$ \\
February & 150 & 224 & $\mathbf{6 6 . 6 9 \%}$ \\
March & 125 & 175 & $\mathbf{7 1 . 4 3 \%}$ \\
April & 224 & 256 & $\mathbf{8 7 . 5 0 \%}$ \\
May & 208 & 289 & $\mathbf{7 1 . 9 7 \%}$ \\
June & 210 & 299 & $\mathbf{7 0 . 2 3 \%}$ \\
July & 223 & 289 & $\mathbf{7 7 . 1 6 \%}$ \\
August & 211 & 278 & $\mathbf{7 5 . 9 0 \%}$ \\
September & 204 & 265 & $\mathbf{7 6 . 9 8 \%}$ \\
October & 198 & 245 & $\mathbf{8 0 . 8 2 \%}$ \\
November & 156 & 198 & $\mathbf{7 8 . 7 9 \%}$ \\
December & 201 & 265 & $\mathbf{7 5 . 8 5 \%}$ \\
\hline
\end{tabular}

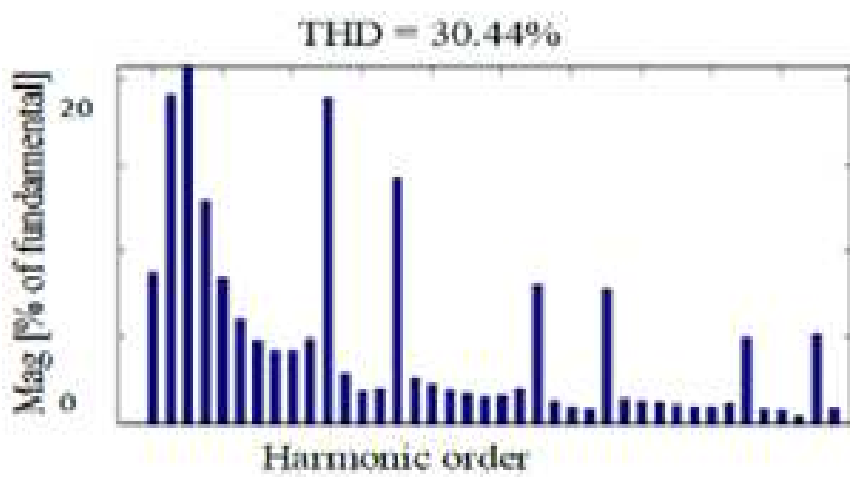

Fig.2: Spectrum analysis of supply current
Power electronic devices are gaining popularity for applications in the field of power transmission and distribution systems. The reactive power (VAR) compensation and control have been recognized [8] as an efficient \& economic means of increasing power system transmission capability and stability.

The use FACTS (Flexible AC Transmission System) devices in a power system can potentially overcome limitations of the present mechanically controlled transmission systems. By facilitating bulk power transfers, these interconnected networks help minimize the need to enlarge power plants and enable neighboring utilities and regions to exchange power. The stature of FACTS devices within the bulk power system will continually increase as the industry moves toward a more competitive posture in which power is bought and sold as a commodity. As power wheeling becomes increasingly prevalent, power electronic devices will be utilized more frequently to insure system reliability and stability and to increase maximum power transmission along various transmission corridors. The FACTS device, such as STATCOM has been introduced more recently which employs a VSI with a fixed DC link capacitor as a static replacement of the synchronous condenser. In a traditional synchronous condenser, the field current of the synchronous motor controls the amount of VAR absorbed/injected and hence in a similar way, the firing instant of the 3-phase inverter controls the VAR flow into or out of the STATCOM. Large numbers of capacitor banks or inductor banks are no more required. Only a fixed set of capacitor provides the required VAR control, with a rapid control of bus voltage and improvement of utility power factor. It offers several advantages over conventional thyristorised converters [9] in terms of speed of response. The STATCOM is a voltage source inverter (VSI) based device, which regulates distribution bus voltage using reactive power compensation. The potential of STATCOM to improve supply quality and increase line utilization in weak distribution networks is well documented [10,11]. However, many of the proposed control strategies assume a stiff, balanced grid source, and this is often not the case in practice. Recently, there has been some research focus on the performance of STATCOM devices operating under unbalanced supply conditions. Direct voltage control algorithms used to compensate for supply unbalance in distribution networks were proposed in [12] and [13]. However, the results in [13] show a relatively slow dynamic response because of the filters employed. Also, both algorithms have been developed for a VSI device interfaced to the distribution network through a simple inductive filter, and have not been tested for the more complex LCL filter considered in this work. A multi-variable control strategy was proposed in [14] for a STATCOM with a LCL filter interface. Although this strategy is shown to achieve good steady state and dynamic responses under balanced and unbalanced supply conditions, it is complex and sensitive to variations in system parameters. The penalty paid for this improvement is in terms of introduction of some harmonics, which requires separate handling using active filtration techniques. Moran et al [15] have shown in details 
how the utilization of Sinusoidal Pulse Width Modulation (SPWM) techniques reduces harmonic distortion. It has also been shown that an increase of modulation index reduces the size of the link reactor and stress on switches which are significant issues in practical implementation. The modeling and analysis of STATCOM steady state and dynamic performance with conventional control method have been studied by Schauder and Mehta [16] using non-linear controller. In $[17,18]$ the dynamic responses and steady state behavior of STATCOM with Space Vector Pulse Width Modulation (SVPWM) has been studied and the advantages of introducing SVPWM inverter with higher values of modulation index are highlighted.

The controllable reactive power allows for a rapid control of bus voltage and power factor at the system or at the load end. To compensate for the distorted current drawn by the rectifiers from the utility grid, the STATCOM and its current controller must have the capability to track source PWM (Pulse Width Modulation) converters. The linear control is more suitable for STATCOM application reported in $[19,20]$. The present paper suggests the design of a linear current controller and voltage controller on the basis of gain and time constant adjustment along with the parameter of the coupling inductor and storage capacitor.

The present paper goes on to develop closed loop model for investigating transient performance of the STATCOM by using controller parameter. First, in Section 2 focuses on state space model of the STATCOM with the system. Secondly, in Section 3 , a current and voltage controllers are designed. The simulated responses with the designed controller parameters are presented. This scheme is both an extension and a significant improvement of the scheme suggested by Shauder et al [16] and Sensarma et al [11]. The results obtained have been compared and appropriate conclusions have been drawn.

\section{MODELING OF THE STATCOM AND}

\section{ANALYSIS}

\subsection{Operating Principle}

As is well known, the STATCOM is, in principle, a static (power electronic) replacement of the age-old synchronous condenser. Fig.3 shows the schematic diagram of the STATCOM at PCC through coupling inductors. The fundamental phasor diagram of the STATCOM terminal voltage with the voltage at PCC for an inductive load in operation, neglecting the harmonic content in the STATCOM terminal voltage, is shown in Fig.4. Ideally, increasing the amplitude of the STATCOM terminal voltage $\vec{V}_{o a}$ above the amplitude of the utility voltage $\vec{V}_{s a}$ causes leading (capacitive) current $\vec{I}_{c a}$ to be injected into the system at PCC as shown in Fig.4.

\subsection{Modeling}

The modeling of the STATCOM, though well known, is reviewed in the lines below, for the sake of convenience. The modeling is carried out with the following assumptions:

1) All switches are ideal

2) The source voltages are balanced

3) $R_{s}$ represents the converter losses and the losses of the coupling inductor

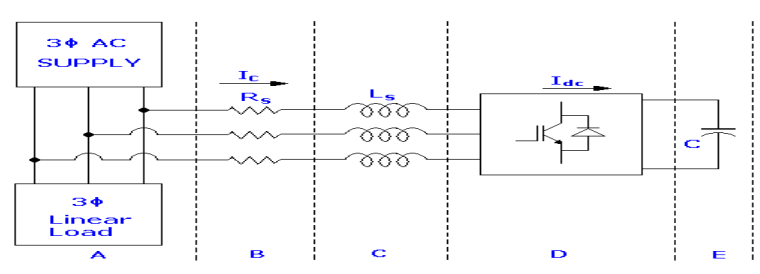

Fig.3: Schematic diagram of STATCOM

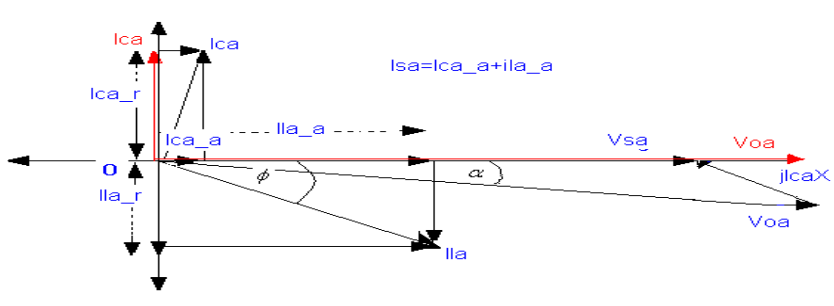

Fig.4: Phasor diagram for inductive load operation

4) The harmonic contents caused by switching action are negligible

The 3-phase stationary $a b c$ coordinate vectors with $120^{\circ}$ apart from each other are converted into $\alpha \beta$ 2-phase stationary coordinates (which are in quadrature). The $\alpha$ axis is aligned with $a$ axis and leading $\beta$ axis and both converted into $d q$ two-phase rotating coordinates. The Park's $a b c$ to $d q$ transformation matrix is

$$
K=\sqrt{\frac{2}{3}}\left[\begin{array}{ccc}
\operatorname{Cos}(\varpi t) & \operatorname{Cos}(\varpi t-2 \pi / 3) & \operatorname{Cos}(\varpi t+2 \pi / 3) \\
\operatorname{Sin}(\varpi t) & \operatorname{Sin}(\varpi t-2 \pi / 3) & \operatorname{Sin}(\varpi t+2 \pi / 3) \\
1 / \sqrt{2} & 1 / \sqrt{2} & 1 / \sqrt{2}
\end{array}\right] \text { (6) }
$$

The actual proposed circuit is too complex to analyze as a whole, so that it is partitioned into several basic sub-circuits, as shown in Fig.3. The 3-phase system voltage $v_{s, a b c}$ lagging with the phase angle $\alpha$ to the STATCOM output voltage $v_{o, a b c}$ and 
differential form of the STATCOM currents are defined in (7) and (8).

$$
\begin{gathered}
v_{s, a b c}=\left[\begin{array}{l}
v_{s a} \\
v_{s b} \\
v_{s c}
\end{array}\right]=\sqrt{\frac{2}{3} V_{s}}\left[\begin{array}{c}
\operatorname{Sin}(\omega t-\alpha) \\
\operatorname{Sin}\left(\omega t-\alpha-\frac{2 \pi}{3}\right) \\
\operatorname{Sin}\left(\omega t-\alpha+\frac{2 \pi}{3}\right.
\end{array}\right] \\
L_{s} \frac{d}{d t}\left(i_{c, a b c}\right)=-R_{s} i_{c, a b c}+v_{s, a b c}-v_{o, a b c}
\end{gathered}
$$

Where, $V_{s}, \varpi, R_{s}$ and $L_{s}$ have their usual connotations. The above voltages and currents are transformed into $d q$ frame

$$
\begin{aligned}
& L_{s} \frac{d}{d t}\left(i_{c q}\right)=-R_{s} i_{c q}-w L_{s} i_{c d}+v_{s q}-v_{o q} \\
& L_{s} \frac{d}{d t}\left(i_{c d}\right)=w L_{s} i_{c q}-R_{s} i_{c d}+v_{s d}-v_{o d}
\end{aligned}
$$

The switching function $S$ of the STATCOM can be defined as follows

$$
S=\left[\begin{array}{c}
S_{a} \\
S_{b} \\
S_{c}
\end{array}\right]=\sqrt{\frac{2}{3} m}\left[\begin{array}{c}
\operatorname{Sin}(w t) \\
\operatorname{Sin}\left(w t-\frac{2 \pi}{3}\right) \\
\operatorname{Sin}\left(w t+\frac{2 \pi}{3}\right)
\end{array}\right]
$$

The modulation index, being constant for a programmed PWM, is given by,

$$
M I=\frac{v_{o, p e a k}}{V_{d c}}=\sqrt{\frac{2}{3} m}
$$

The STATCOM output voltages in $d q$ transformation are

$$
v_{o, q d o}=m\left[\begin{array}{lll}
0 & 1 & 0
\end{array}\right]^{T} v_{d c}
$$

The dc side current in the capacitor in $d q$ transformation

$$
i_{d c}=m\left[\begin{array}{lll}
0 & 1 & 0
\end{array}\right]\left[\begin{array}{lll}
i_{c q} & i_{c d} & i_{c o}
\end{array}\right]^{T}
$$

The voltage and current related in the dc side is given by

$$
\frac{d v_{d c}}{d t}=\frac{m}{C} i_{c d}
$$

The complete mathematical model of the STATCOM in $d q$ frame is obtained as given in (15)

$$
\frac{d}{d t}\left[\begin{array}{c}
i_{c q} \\
i_{c d} \\
v_{d c}
\end{array}\right]=\left[\begin{array}{ccc}
-\frac{R_{s}}{L_{s}} & -w & 0 \\
w & -\frac{R_{s}}{L_{s}} & -\frac{m}{L_{s}} \\
0 & \frac{m}{C} & 0
\end{array}\right]\left[\begin{array}{c}
i_{c q} \\
i_{c d} \\
v_{d c}
\end{array}\right]+\frac{V_{s}}{L_{s}}\left[\begin{array}{c}
-\operatorname{Sin} \alpha \\
\operatorname{Cos} \alpha \\
0
\end{array}\right]
$$

\subsection{Steady State and Transient Analysis}

The detailed steady state and transient responses with the Table.II are given in Fig.5-8 and responses suggest the static and dynamic conditions of the STATCOM. It can be seen that the transient responses take about one and half power cycle to reach at their steady state values.

Table 2: It shows the system parameters

\begin{tabular}{|l|l|l|l|}
\hline S1 & Parameters & Symbol & Values \\
\hline 1 & Frequency & $f$ & $50 \mathrm{~Hz}$ \\
\hline 2 & Angular Frequency & $W$ & $314 \mathrm{rad} / \mathrm{sec}$ \\
\hline 3 & $\begin{array}{l}\text { RMS line-to-line } \\
\text { Voltage }\end{array}$ & $V_{s}$ & $230 \mathrm{~V}$ \\
\hline 4 & Coupling Resistance & $R_{s}$ & $1.0 \Omega$ \\
\hline 5 & Coupling Inductance & $L_{s}$ & $5.0 \mathrm{mH}$ \\
\hline 6 & DC-link capacitor & $\mathrm{C}$ & $500 \mu F$ \\
\hline 7 & Modulation Index & $\mathrm{M}$ & 0.979 \\
\hline 8 & Phase angle & $\alpha$ & $\mp 50$ \\
\hline 9 & Load Resistance & $R_{L}$ & $52 \Omega$ \\
\hline 10 & Load Inductance & $L_{L}$ & $126 \mathrm{mH}$ \\
\hline 11 & Load Power factor & $\phi$ & 0.79 \\
\hline
\end{tabular}

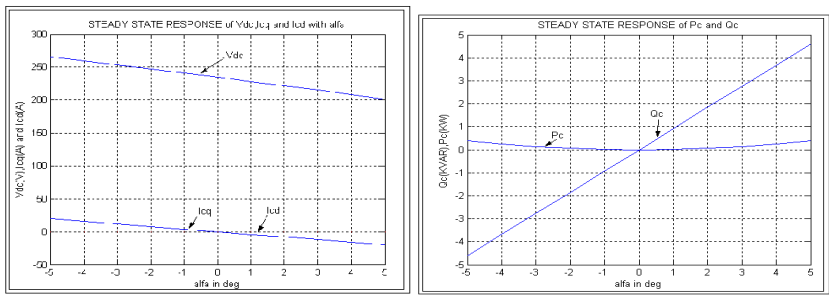

(a)

(b) 


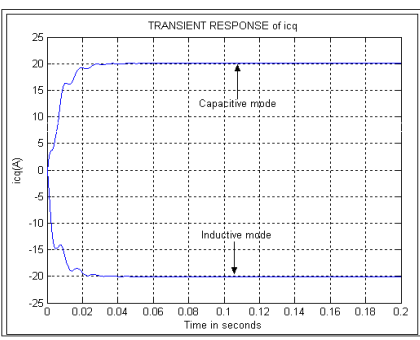

(c)

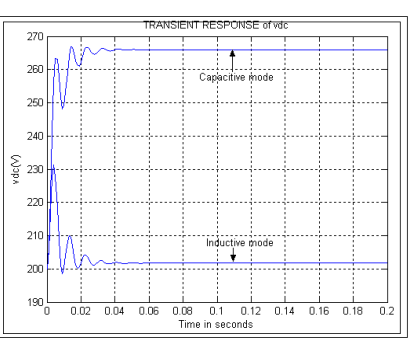

(d)
Fig.5: Responses: (a) steady state of $I_{c q}, I_{c d}$ and $V_{d c}$, (b) steady state of $P_{c}$ and $Q_{c}$, (c) transient of $i_{c q}$ in capacitive and inductive and (d) transient of $v_{d c}$ in capacitive and inductive

\section{DESIGN OF CONTROLLERS:}

$$
\frac{d}{d t}\left[\begin{array}{l}
i_{c q} \\
i_{c d}
\end{array}\right]=\left[\begin{array}{cc}
-\frac{R_{S}}{L_{S}} & -\omega \\
\omega & -\frac{R_{S}}{L_{S}}
\end{array}\right]\left[\begin{array}{l}
i_{c q} \\
i_{c d}
\end{array}\right]+\frac{1}{L_{S}}\left[\left[\begin{array}{c}
v_{s q} \\
v_{s d}
\end{array}\right]-\left[\begin{array}{c}
v_{o q} \\
v_{o d}
\end{array}\right]\right]
$$

With the assumption of the system voltage and STATCOM output voltage are in phase and hence the equation (15) can be modified as given in equation (16). So the equation (16) is a Multiple Input and Multiple Output (MIMO) system and its input and output are given as

$$
[u]=\left[\begin{array}{c}
v_{o q} \\
v_{o d}
\end{array}\right],[y]=\left[\begin{array}{l}
i_{c q} \\
i_{c d}
\end{array}\right]
$$

The block diagram of the STATCOM in d-q transformation as per (16) is shown in Fig.6.The instantaneous voltage of the system and the STATCOM are independent, but the active and the reactive currents are coupled with each other through the reactance of the coupled inductor. So it is very essential to decouple the active and reactive current from each other and design the controller for tracking the required value.

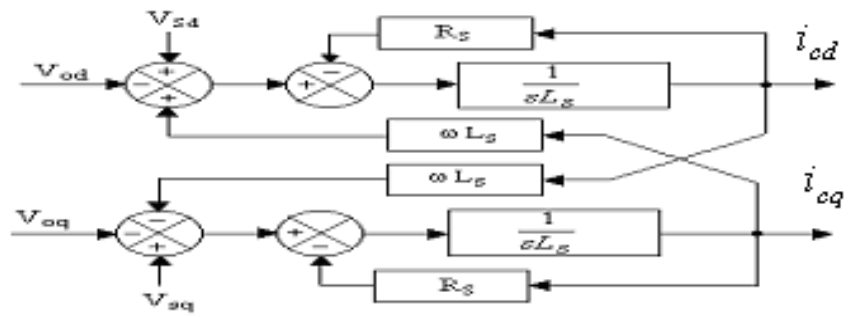

\subsection{Design of Current Controller:}

The current controller design for the above system can be done using the strategy [15-16] attempts to decouple the $d$ and q axes equations, so that the MIMO system reduces to two independent Single Input Single Output (SISO) system. Hence, the control inputs $v_{o d}$ and $v_{o q}$ are configured as

$$
\begin{aligned}
& v_{o q}=-v_{o q}^{*}-w L_{s} i_{c q}+v_{s q} \\
& v_{o d}=-v_{o d}^{*}+w L_{s} i_{c d}+v_{s d}
\end{aligned}
$$

The equation (19) can be obtained by replacing (16) by (18). Hence each row of (19) is independent of each other and thus defines an independent SISO system. Conventional frequencydomain design methods can now be directly applied for current controller. Taking the Laplace transformation of both sides of (19) and rearranging terms are given by (20) and their decoupled SISO system is shown in Fig.7.

$$
\begin{aligned}
& {\left[\begin{array}{c}
i_{c q} \\
\dot{i}_{c d}
\end{array}\right]=\left[\begin{array}{cc}
-\frac{R_{S}}{L_{S}} & 0 \\
0 & -\frac{R_{S}}{L_{S}}
\end{array}\right]\left[\begin{array}{l}
i_{c q} \\
i_{c d}
\end{array}\right]+\frac{1}{L_{S}}\left[\begin{array}{c}
v_{o q}^{*} \\
v_{o d}^{*}
\end{array}\right]} \\
& G_{q}(s)=\frac{I_{q}(s)}{V_{o q^{*}}^{*}(s)}=\frac{1}{R_{s}+s L_{s}}, G_{d}(s)=\frac{I_{d}(s)}{V_{o d}^{*}(s)}=\frac{1}{R_{s}+s L_{s}}
\end{aligned}
$$

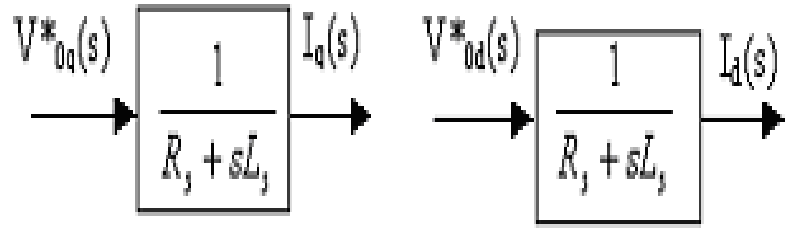

Fig.7: Current control of inverter of equivalent decoupled SISO systems

For similar dynamic behaviour of the $d$ and $q$-axis currents, both the $d$ and $q$-axis controllers are identical and its transfer function is given in (21)

$$
G_{i}(s)=\frac{I_{c q^{(s)}}}{V_{o q^{*}}^{*}(s)}=\frac{I_{c d}(s)}{V_{o d^{*}}^{*}(s)}=\frac{1}{R_{s}+s L_{s}}
$$

Fig.6: Equivalent Diagram on a.c.side of STATCOM 
The transfer function of a PI controller is

$$
G_{p i}(s)=K\left(1+\frac{1}{s \tau}\right)=K_{p}+\frac{K_{i}}{s}
$$

With $K_{p}=K, K_{i}=\frac{K}{\tau_{i}}$. The transfer function in open loop of

PI controller associated with the transfer function on the a.c. system is

$$
\left[G_{p i}(s) \cdot G_{i}(s)\right]=K\left[1+\frac{1}{s \tau}\right]\left[\frac{1 / R_{S}}{1+s / L_{S} / R_{S}}\right]
$$

While taking $\tau_{i}=\frac{L_{S}}{R_{S}}$ and on simplification reduces to

$$
\left[G_{p i}(s) \cdot G_{i}(s)\right]=\frac{K}{s L_{s}}
$$

The closed loop transfer function is

$$
T=\frac{1}{1+s \frac{L_{S}}{K}}
$$

Thus the system behaves like a first order with an apparent time constant as

$$
\tau_{i}=\frac{L_{s}}{K}
$$

The gain of $\mathrm{K}$ can be adjusted such a way that if it is increased too high then the system behaves as second order, otherwise responses very slow. Hence the numerical values for $K_{p}$ and $K_{i}$ are decided from the circuit parameters $L_{S}$ and $R_{S}$ from the required value of $\mathrm{K}$. So the parameters of PI controller are defined as

$$
K_{p}=K, K_{i}=\frac{K R_{s}}{L_{S}}
$$

Where, $\tau_{i}=\frac{L_{s}}{K_{p}}$ which is taken as 0.3 mseconds and with the parameters given in Table-II, value of $K_{p i}=16.9$ and $K_{i i}=3.3 \times 10^{3}$ are calculated. These parameters are used in $d$ and $q$ - axis current controller. The structure of the effective closed loop system is shown in Fig. 8 and is replicated in both the $d$ and $q$-axis current controllers. Bode plot of the system with controller is shown in Fig.9, which is a first order system.

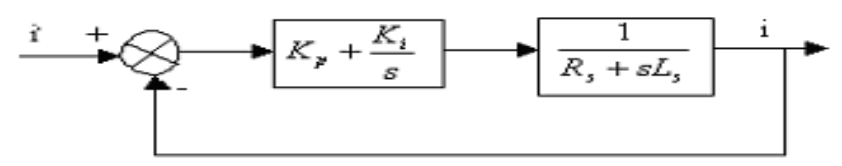

Fig.8: Effective closed loop current control system

\subsection{Design of Voltage Controller:}

The relation between dc voltage $v_{d c}$ and dc current $i_{d c}$ is

$$
v_{d c}=\frac{1}{C} \int i_{d c} d t
$$

The transfer function can be written as

$$
G_{v}(s)=\frac{V_{d c}}{I_{d c}}=\frac{1}{s C}
$$

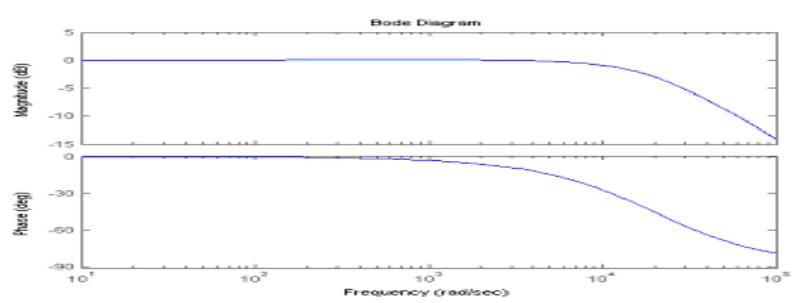

Fig.9: Bode plot of the system with PI controller

Neglecting the power loss in the source resistance and power losses in the switches, balancing the power on both sides,

$$
v_{s d} i_{c d}=v_{d c} i_{d c}
$$

From the above equation, we have

$$
\frac{i_{d c}}{i_{c d}}=\frac{v_{s d}}{v_{d c}}=\frac{V_{s}}{V_{d c}}=\frac{230}{500}=0.46
$$


With $V_{d c}$ as the reference, the voltage control loop is shown in Fig.10 and it consists of inner $d$-axis current control loop. The active power is supplied by the $d$-axis current which is nothing but the ripple current of the capacitor. To make the steady state error of the voltage loop zero Proportional control is adopted here and it produces the reference $d$-axis current for the control of the $d$-axis current. The design of voltage controller is as follows:

The open loop transfer function of DC bus voltage controller is

$$
G_{o p}=\frac{K^{*} K_{d c}}{s C}
$$

The closed loop transfer function with unity feed back gain is

$$
G_{c l}=\frac{1}{1+\frac{s C}{K^{*} K_{d c}}}
$$

Where, $\tau_{v}=\frac{C}{K * K_{d c}}$ and taking $\tau_{v}=1$ msecond and with the parameters of Table. I, the value of $K_{d c}=1.08$

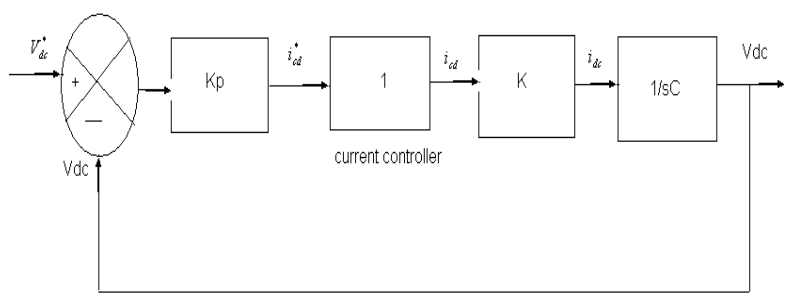

Fig.10: DC link voltage control loop

Then Proportional Integral controller is considering for the voltage control. Hence, the transfer function of PI controller in (22) is associated with the transfer function on dc side is

$$
\left[G_{v}(s) \cdot G_{p i}(s)\right]_{o l}=K\left(1+\frac{1}{s \tau_{v}}\right)\left(\frac{1}{s C}\right)
$$

After taking $\tau_{v}=C$ and on simplification

$$
\left[G_{v}(s) \cdot G_{p i}(s)\right]_{o l}=K\left(\frac{1+s \tau_{v}}{s^{2} \tau_{v}^{2}}\right)
$$

The transfer function in closed loop

$$
\left[G_{v}(s) \cdot G_{p i}(s)\right]_{c l}=\left(\frac{1+s \tau_{v}}{1+s \tau_{v}+\frac{s^{2} \tau_{v}^{2}}{K}}\right)
$$

So the system behaves like a second order system. As $\tau_{v}>>\frac{\tau_{v}^{2}}{K}$ and magnitude plot in Fig.9 shows the initial slop at break point is approximately $-20 \mathrm{db} /$ decade and hence it reduces to first order system. The value of $\mathrm{K}$ can be determined form root locus with approximate settling time as given in (37) and implementation block diagram is shown in Fig.14.

$$
K_{p v}=K=0.15, K_{v i}=\frac{K}{C}=200
$$

The control loop shown in Fig.11 It is interesting to note that the controllers designed for linear loads are found to be capable of working with non-linear load too with minor but essential modifications. The only change is the inclusion of a stage of the high pass filter (HPF) used before the $d$-axis controller. Here also three different PI-controllers are needed to control $q$-axis current, $i_{c q}, d$-axis current,$i_{c d}$, and the DC-link voltage, $v_{d c}$. The reference input for the $i_{c d}$ controller is generated from the sum of the output of the DC-link voltage controller and the high frequency components of the load current. The adopted scheme is a usual one and also used in the industry.

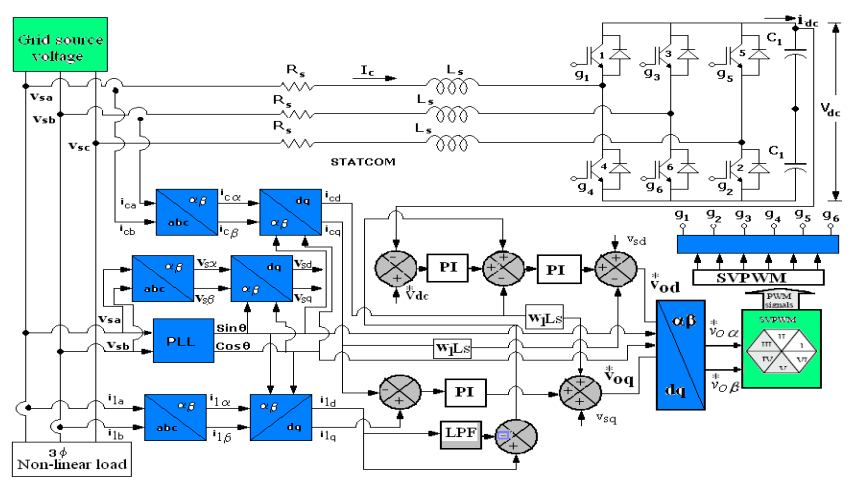

Fig.11: Implementing scheme

\section{SIMULATION RESULTS:}

The simulated plots of the grid $v_{s a}$ and $i_{s a}$ (when STATCOM is off) are shown in Fig.12 (current magnitude of 3.504A (rms), as sensor multiplying factor is 10) respectively. It shows rectangular shape of the current waveform of the diode rectifier 
without capacitor at the DC output voltage. It is easy to see that the harmonics are reasonably reduced. It is very interesting to note that when STATCOM is on the simulated responses of the grid $v_{s a}$ and $i_{s a}$ (harmonics eliminated and var compensated which improves power factor) are in full agreement with each other (shown in Fig.13). The harmonic spectrum of the grid $i_{s a}$ (rectifier load phase-a current) in simulation are plotted in Fig.14 (a). It depicts that both the plots compare remarkably well (as simulation shows that $T H D_{i}$.of the grid $i_{s a}$ (load current) is $31.07 \%$ ). There is a close agreement of $T H D_{i}$ of the grid $i_{s a}$ in simulation (where $T H D_{i}=12.05 \%$ ) as plotted in Fig.14 (b).
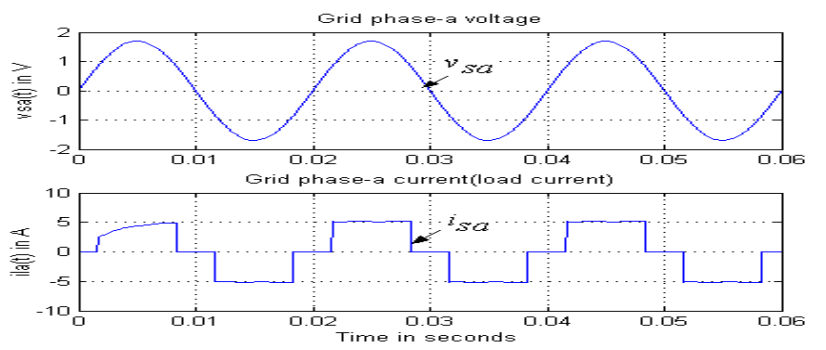

Fig.12: Simulated traces of the $v_{s a}$ and $i_{s a}$ (for 3.506) when the STATCOM is off condition (for 3.504A as sensor multiplying factor 10 )
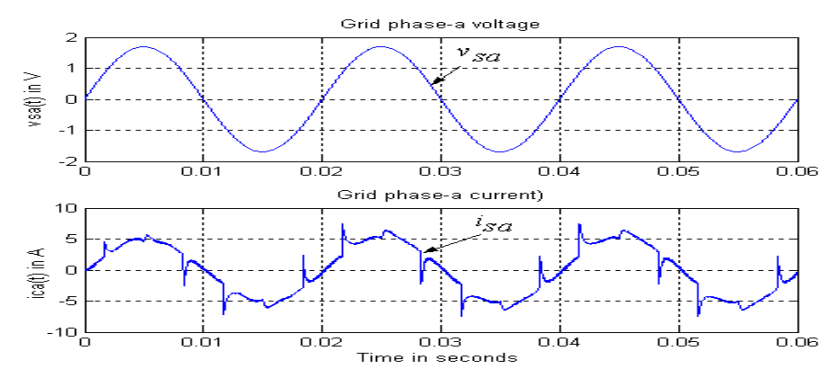

Fig.13: Simulated records of the $v_{s a}$ and $i_{s a}$ (for 3.506A) when the STATCOM is on

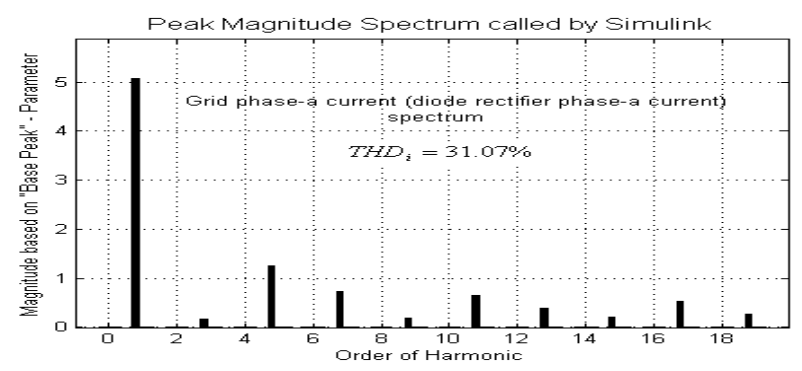

(a)

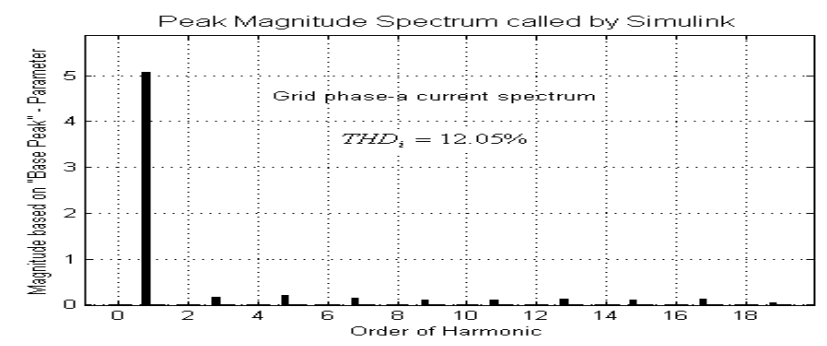

(b)

Fig.14: (a) Simulated waveforms of harmonic spectrum of $i_{s a}$ when the STATCOM is switched off $\left(T H D_{i}=31.07 \%\right)$, and

(b) simulated at the STATCOM is on $\left(T H D_{i}=12.05 \%\right)$

\section{CONCLUSIONS}

The investigations of the performance of the STATCOM for the harmonic reduction with non-linear loads have been carried out. With proposed model catering non-linear loads have been performed very well. The STATCOM works as an active filter. The simulated waveforms confirm the validity of the control strategy. It has also been shown that the interaction between a STATCOM device and a supply system makes the rural consumers healthy and wealthy.

\section{REFERENCES}

[1] J.-C. Wu, H.-L. Jou, and Y.-T. Feng, "Novel circuit topology for three-phase active Power filter," IEEE Trans. Power Del., vol. 22, no. 1, pp. 444-449, Jan 2007.

[2] M. H. Abdel-Rahman, F. M. H. Youssef, and A.A. Saber, "New static var compensator control strategy and coordination with under-load tap changer," IEEE Trans. Power Del., vol. 21, no. 3, pp.1630-1635 Jul. 2006.

[3] C.K.Duffey and R.P.Stratford, "Update of Harmonic Standard IEEE-5 19: Recommended Practices and Requirements for Harmonic Control in Electric Power Supply Systems." IEEE Trans.IAS,pp. 1025-1034, Nov/Dec. 1989.

[4] S Z. Shuai, A. Luo, R. Fan et al, "Injection branch design of injection type hybrid active power filter," Autom. Elect. Power Syst., vol. 31, no. 5, pp. 5760,Jun. 2007

[5] An Luo, Zhikang Shuai, Wenji Zhu, and Z. John Shen," Combined System for Harmonic Suppression and Reactive Power Compensation" IEEE Transactions on Industrial Electronics, Vol. 56, no.2,February 2009.

[6] Z. Chengyong, L. Xiangdong, and L. Guangkai,"Parameters Optimization of VSC-HVDC control system based on simplex algorithm," in Proc. 
IEEE Power Eng. Soc. General Meeting, 2007, pp. 17.

[7] K.-K. Shyu, M.-J. Yang, Y.-M. Chen, and Y.F.Lin,"Model reference adaptive control design for a shunt active-power-filter system," IEEE Trans. Ind. Electron., vol. 55, no. 1, pp. 97-106, Jan. 2008

[8] A.T. Johns, A.Ter-Gazarian and D.F.Wame,'Flexible ac transmission systems (FACTS)", IEE Power and Energy Series, London, U.K.

[9] R.M.Mathur and R.K. Varma, "Thyristors-based FACTS Controllers for Electrical Transmission Systems, IEEE Press", Wiley-Interscience Publication.

[10] Z. Saad-Saoud, M. L. Li:jboa, J. B. Ekanayake, N. Jenkins, and G. Strbac, "Application of STATCOMs to wind farms," IEE Proceedings. Generation, Transmission \& Distribution, vol. 145, pp. 51 1-518, 1998

[11] P. S. Sensarma, K. R. Pa.diayar and V. Ramanarayanan, "Analysis and Performance Evaluation of a Distribution STATCOM for Compensating Voltage Fluctuations," IEEE Transactions on Power Delivery, vol 16. no. 2, April $200 \mathrm{I}$.

[12] C. Hochgrnf and R. H. Lasseter, "Statcom controls for Operation with Unbalanced Voltages", IEEE Transactions on Power Delivery. vol. 13, no. 2, April 1998.

[13] S. Chen, G. Joos and L. T. Moran, "Dynamic Performance of PWM STATCOMs Operating under Unbalance and Fault Conditions in Distribution Systems", in Proc. of IEEE Power Engineering Socieg WififterM eeting, 2001, vol. 2, pp. 950-955.

[14] G. Ledwich and A. Ghosh, "A flexible DSTATCOM operating in voltage or current control mode", IEE Proc.-Gener. Trunsm.Distrbi., vol. 149, no. 2, March 2002.

[15] L.T. Moran, P.D.Ziogas and G.Joos, "Analysis and Design of a Three-Phase Synchronous Solid- State Var Compansator", IEEE Trans. Industry Application, Vol. 25, No. 4, 1989, pp. 598-608.

[16] C.Shauder and H.Mehta, "Vector analysis and control of advanced static VAR compensators", IEE Proc, 140, No. 4, July 1993.

[17] Draou, M. Benghanem and A. Tahiri, "Multilevel Converter and VAR Compensation", Power Electronics Handbook", pp.599-611, Academic Press, 2001.

[18] M.Sengupta,J.K Moharana and A.Sengupta," Study on an Advanced Static VAR Compensator switched from a Space Vector PWM inverter -Analysis, simulation and comparison with the conventional sinusoidal PWM, NPEC 2003, IIT Bombay,16-17 Oct 03 pp 72-78.

[19] D.M.Brod and D.W.Novotny, "Current control of VSI- PWM inverter "IEEE Trans.Industrial Appl, Vol.IA-21, pp.562- 570, July/Aug.1985.S.Buso,
L.Malesani and P.Mattavelli, "Comparison of Current Control Techniques for Active Filter Application "IEEE Trans. Industrial Electronics, Vol.45, No.5, pp.722-729, October 1998.

[20] A.M. Kulkarni and K.R. Padiyara, "Design of Reactive Current and Voltage Controllers of Static Condenser", Power and Energy System, Vol.19, No.6, pp.397-410, 1997. 